\title{
Analysis of Risk Factors of Myocardial Infarction in the Young (<40 years)
}

\author{
Authors \\ Pothuluraiah Chary Katakam ${ }^{1 *}$, Satish Srinivas $\mathbf{P}^{2}$, Satya Kumari Dasari ${ }^{3}$, Tirumala \\ Rao M.V.V ${ }^{4}$,Taraka Ravi Kiran Komanapalli ${ }^{5}$, Divyamanikanta Swaroop Palla \\ *Corresponding Author \\ Pothuluraiah Chary Katakam
}

\begin{abstract}
Background: Coronary artery disease (CAD) mostly occurs in persons older than 45 years of age. In India, CAD manifests almost a decade earlier than in Western countries. This study was done to study the clinical profile and risk factors in young patients presenting with acute myocardial infarction (AMI).

Patients and Methods: One hundred and twenty six consecutive patients presenting with AMI at less than 40 years of age were studied for risk factors.

Results: Out of 126 patients, 109 were male. Mean age was 35.94 yrs. 92 patients (73\%) were smoker, 66 were hypertensive (52\%), 24 were diabetic (19\%). Family history of CAD was present in 82(65\%) patients. Dyslipidaemia in 92 patients (73\%).

Conclusion: AMI in young more common in male. Anterior wall MI is most common. Smoking, hypertension, low HDL and high triglycerides are the major risk factors.

Keywords: Coronary artery disease, myocardial infarction, risk factors.

\section{Introduction}

Coronary artery disease (CAD) is the leading cause

risk factor profile and pattern of coronary artery involvement in AMI in young, soothe purpose of the study.
\end{abstract} of death in the West. Acute myocardial infarction (AMI) among young is relatively uncommon. CAD appears a decade earlier in India than other countries. Premature coronary artery disease is defined as coronary artery disease occurring before the age of 40 years ${ }^{1}$. Young patients have different risk factors, clinical presentation and prognosis than the older patients. In some studies, from India, the percentage of patients below the age of 45 years suffering from acute myocardial infarction (AMI) is reported as high as $25-40 \%^{2}$.

This study aims at evaluating the risk factors involved in the development of myocardial infarction and the clinical spectrum in the younger ( $<40$ years) age group. There are few studies of

\section{Materials and Methods}

The study was conducted at the intensive cardiac care unit of Government General Hospital, Rangaraya Medical College during the period of September 2018 to February2019. 126 patients, aged $<40$ years, admitted with the clinical features of myocardial infarction with ECG changes suggestive of MI, elevated CKMB and SGOT were taken as cases.

Person who smokes > 10 cig/day, are smokers. Hypertension was considered by documented history of hypertension on medication or BP $>140 / 90 \mathrm{~mm}$ Hg. Diabetes Mellitus was considered either by documented history of treatment or with a 
fasting blood sugar level $\geq 126 \mathrm{mg} \%$ and post prandial blood sugar level $\geq 200 \mathrm{mg} \%$ and $\mathrm{HbA1C}$ levels >7. A lipid profile with, HDL level > $50 \mathrm{mg} / \mathrm{dl}$, LDL level > $130 \mathrm{mg} / \mathrm{dl}$, total cholesterol $>200 \mathrm{mg} / \mathrm{dl}$ were taken as Dyslipidemia. Patients categorized as type A \& type B personality traits. A detailed family history, socioeconomic status, occupation, diet and lifestyle were obtained. BMI $>25$ taken as obesity and weight/hip ratio $>0.8$ in females $>0.9$ in males were taken as abnormal.

\section{Results}

In our study $76 \%$ of the patients were in the age group of 35-40.

Out of the 126 cases under study 109 were males and 17 were females, females were elder to their male counterparts.

$65 \%$ of patients with myocardial infarction had positive family history.

Nearly $72 \%$ of smokers developed myocardial infarction.

Out of the 126 cases, diabetes mellitus was found 24 cases.

$80 \%$ of young coronary artery disease subjects were come from low socioeconomic and middle-income segment of the society.

Out of the 126 patients $73 \%$ were found to have dyslipidemia.

$52 \%$ of cases with were found to have a history of Hypertension or were newly diagnosed to have hypertension.

92 patients had a BMI above the desirable value clearly indicating that obesity increases the risk of myocardial infarction.

$73 \%$ of the women and $67 \%$ of men had waist hip ratio above the desired level.

$38 \%$ of the patients are Type A personalities with an evidence of stressful environment.

The most common site of infarction was found to be anterior wall accounting for $55 \%$ of cases.
Table: 1 Percentage of risk factors

\begin{tabular}{|l|l|}
\hline Males & $86 \%$ \\
\hline Smoking & $72 \%$ \\
\hline Dyslipidemia & $73 \%$ \\
\hline Family History & $65 \%$ \\
\hline Low Socioeconomic status & $53 \%$ \\
\hline Hypertension & $52 \%$ \\
\hline Sedentary Lifestyle & $40 \%$ \\
\hline Psychosocial Stress & $38 \%$ \\
\hline Obesity & $73 \%$ \\
\hline Diabetes Mellitus & $19 \%$ \\
\hline
\end{tabular}

Table: 2 Combinations of Risk Factors in MI

\begin{tabular}{|l|c|}
\hline HT + Obesity + DM + Dyslipidemia & 7 \\
\hline Dyslipidemia + Obesity + DM & 7 \\
\hline Obesity + Hypertension & 33 \\
\hline Obesity + Diabetes mellitus & 8 \\
\hline Obesity + Dyslipidemia & 41 \\
\hline
\end{tabular}

\section{Discussion}

Key factors influencing the development of myocardial infarction were non modifiable risk factors such as age, sex, family history.

In this study, risk factor analysis showed that smoking, hypercholesterolemia, positive family history, hypertension, obesity was frequently associated with young myocardial infarction patients.

\section{Smoking}

In our study $72 \%$ of the patients were smokers, all of them are males. In earlier studies to similar observations have been made i.e. Jeyachandran et al., $^{3}(53 \%)$, Gupta ${ }^{[4]}$ et al., Bergstrand ${ }^{[5]} \mathrm{R}$ et al., Gower $^{[6]} \mathrm{MC}$ et al., (89\%). Dwivedi ${ }^{[7]}$ et al.,(61.42\%). Smoking is probably the single most important modifiable risk factor. There is a strong relationship between cigarette smoking and coronary artery heart disease in young individuals.

\section{Hypercholesterolemia}

In our study $73 \%$ of patients were found to have dyslipidemia. Similar observations have been made in other studies i.e. David ${ }^{[11]} \mathrm{JE}$ et al in (68\%), PK Biswas A Dasbiswas S Roy ${ }^{[8]}$ et al., (30.6\%). Majority of patients with myocardial infarction haddyslipidemia. The risk is also closely related to plasma LDL cholesterol, and inversely related to HDL cholesterol concentration. 


\section{Family History}

In this study $65 \%$ of the patients were found to have positive family history. In earlier studies too similar observation have been made i.e. Marty ${ }^{[9]}$ AK Das AK et al., (28\%), PK Biswas A Dasbiswas S Roy ${ }^{[8]}$ et al., (11.3\%), Dwivedi ${ }^{[7]}$ et al., (42.8\%).

\section{Age Sex Ratio}

In this study males were $86 \%$ and females were $14 \%$ (Male \& Female ratio is 6.4:1). Significantly major risk factors like smoking, psychosocial stress and hypertension were high among men as compared to women. In females the risk of developing coronary artery disease started 10 years later than male. The most common age groups affected were between 37 to 40 years. This denotes increasing incidence of myocardial infarction with increase in age. Similar observations have been made in other studies also i.e. Dwivedi et al. ${ }^{[7]}(4: 1)$, Bikanes study (8:1). Males were commonly affected especially in the younger age group. Females showed an increased risk of myocardial infarction towards the later stages of life presumably due to hormonal factors.

\section{Hypertension}

In this study $52 \%$ of the patients were found to have high blood pressure, Similar observation have been found in other studies also i.e. Marty ${ }^{[9]}$ AK Das et al., (28\%), Nitter Haugh ${ }^{[10]}$ et al., (24\%) Dwivedi ${ }^{[7]}$ et al., (51.42\%).

\section{Psychosocial Stress}

In this study $38 \%$ of patients were found to have psychological stress. Similar observations have been made in other study also i.e. Marty ${ }^{[9]}$ AK Das AK et al.,(40\%).

\section{Obesity}

In this study $73 \%$ of patients were found to have obesity. Similar observations have been made in other studies also i.e. Dwivedi ${ }^{[7]}$ et al., (35.71\%), PK Biswas $A^{[8]}(9.7 \%)$.

\section{Diabetes Mellitus}

In our study $19 \%$ of patients were found to have Similar observations have been made in other studies also i.e. Marty ${ }^{[9]}$ AK Das AK et al., (18\%), PK Biswas $A^{[8]}(9.7 \%)$, Dwivedi ${ }^{[7]}$ et al.,(7.14\%). The incidence of diabetic mellitus in young myocardial infarction patients was comparatively less than the incidence of other risk factors.

\section{Conclusions}

$>$ Most common age group affected was between 36 to 40 years showing that risk of myocardial infarction increase proportionately with increasing age.

Family history of myocardial infarction is an important risk factor contributing to myocardial infarction in young individuals. This is probably due to an inter play of both genetic and environmental factors.

High prevalence of chronic heavy smoking can explain why young subjects who have smoking as a sole conventional risk factor develop premature coronary artery heart disease.

$>$ The obesity and Dyslipidemia were an important risk factors in young myocardial infarction patients probably due to the increasing incidence of sedentary lifestyle.

$>$ Prevention can aim at modifying the risk factors like cessation of smoking, reduction of weight, reduction of salt intake, dietary changes, increase physical activity and control of psychosocial stress. This will have a tremendous impact in reducing the incidence of myocardial infarction in the young.

\section{References}

1. ENAS EA, Dhawan J, Petkar S et al. Study on coronary artery disease in Asian Indians.

2. Girija G Risk factors profile of patient with acute myocardial infarction in Vijaya Ragavan G Cardiovascular disease prevention Trivandrum78-83.

3. Jeyachandran $\mathrm{R}$ Sathayamathy I, Subramanyan K. et al., Coronary artery disease in found Indian Heart Journal. 1996; 37112-118.

4. Gupta SR, Gupa SK, Reddy KN et al coronary artery disease in young Indian subjects Indian Heart Journal. 1996; 4824145.

5. Bergstrand R Vedin A wilhelnsson $\mathrm{C}$ et al 
Myocardial infarction among men <

40british heart jounral.1989;41-715-22.

6. Gower $\mathrm{MC}$ et al Myocardial infarction before age 30 Risk factor and angiographic analysis "American Journal of Cardiology". 1993; 328 538- 45.

7. Coronary artery disease in the young; Heredo familial or faulty life style or both by: S DWIVEDI, GIRISH DWIVEDI, A CHATURVEDI, SANJIV SHARMA, journal Indian academy of clinical medicine Vol.No.3, Oct - Dec2000.

8. PK Biswar, A Dasbiswas S Roy et al risk factors and angiographic profile of coronary artery disease of young JIMA, 199222-26.

9. Marty A.K. Das AK et al prognostive significations of risk factors in AMI in young. Indian Heart Journal. 1991 13108111.

10. Nitter Hauge S Erickssen J Thawlow E et al., "Angiographic and risk factor characteristic of subjects with early onset of ischemic heart disease British heart journal. 1987; 1144477-82.

11. David JE Mallal FJ Cheitlinm ND Coronary artery disease in young patients. Arteriographic and clinical review of 40 cases aged 35 and under American heart journal 1977.74:318-31. 